\title{
Vinorelbine Tartrate Oral
}

National Cancer Institute

\section{Source}

National Cancer Institute. Vinorelbine Tartrate Oral. NCI Thesaurus. Code C85457.

An orally bioavailable tartrate salt of vinorelbine, a semisynthetic vinca alkaloid with potential antineoplastic activity. Vinorelbine binds to tubulin, thereby inhibiting tubulin polymerization into microtubules and spindle formation and resulting in apoptosis of susceptible cancer cells. Inhibition of mitotic microtubules correlates with antitumor activity, whereas inhibition of axonal microtubules seems to correlate with vinorelbine's neurotoxicity. Compared to related vinca alkaloids, vinorelbine is more selective against mitotic than axonal microtubules in vitro, which may account for its decreased neurotoxicity. This agent is also a radiation-sensitizing agent. 